\title{
Effect of Conductivity of the Aqueous Solution on the Size of Printable Nanoparticle
}

\author{
Mi-Hyun Oh, ${ }^{1}$ Nam-Soo Kim, ${ }^{2}$ and Sun-Mee Kang ${ }^{3}$ \\ ${ }^{1}$ Department of Bio-Chemical Engineering, SeoKyeong University, Seoul 136-704, Republic of Korea \\ ${ }^{2}$ Department of Metallurgical and Materials Engineering, The University of Texas at El Paso, El Paso, TX 79968, USA \\ ${ }^{3}$ Department of Electronics Engineering, SeoKyeong University, Seoul 136-704, Republic of Korea
}

Correspondence should be addressed to Sun-Mee Kang, smkang@skuniv.ac.kr

Received 9 December 2011; Accepted 2 April 2012

Academic Editor: In-Kyu You

Copyright (C) 2012 Mi-Hyun Oh et al. This is an open access article distributed under the Creative Commons Attribution License, which permits unrestricted use, distribution, and reproduction in any medium, provided the original work is properly cited.

\begin{abstract}
Direct writing technology using nano/microsize particles in aqueous solution is currently one of the leading candidates to bring a substantial advancement to the technical arena. However, little is known about an effect of conductivity of the solution including metal ions on nanoparticle size for the direct writing technology. It is believed that conductivity of solution can influence the size of particles in reducing environmental of aqueous solutions. In this study parameters which affect electric conductivity in solution were characterized by changing concentration of copper ion, concentration of surfactants, and anion of metal compounds. The mobility of ion in aqueous media with respect to copper ion concentration was the most pronounced factor to control the size of created copper nanometals in water. However, due to the high reactivity on large surface area, the nanocopper metal was oxidized in water. The electric conductivity varied in the range of 7 to $360 \mathrm{mS} / \mathrm{cm}$ when $\mathrm{Cu}\left(\mathrm{NO}_{3}\right)_{2} \cdot 3 \mathrm{H}_{2} \mathrm{O}$ dissolved in water from $0.03-$ $3.0 \mathrm{~mol} / \mathrm{dm}^{3}$. In this condition, the size of nano particles can vary from 10 to $500 \mathrm{~nm}$. Various concentrations of surfactants and two anion $\mathrm{Cu}$ compounds used to vary the conductivity of the solution to verify the effect of electric conductivity of solution on the particle size. Decreasing the conductivity had a corresponding effect on the particle size. The electric conductivity was decreased from 67 to $56 \mathrm{mS} / \mathrm{cm}$ by adding surfactant from 0.1 to $0.5 \mathrm{~mol} / \mathrm{dm}^{3}$ consequently, the particle sizes were decreased from 89 to $21 \mathrm{~nm}$. Copper nitrate and copper chloride were used to verify the anion effect on electrical conductivity and particle sizes. This effect was not dependent on the kind of ions chosen to change the conductivity. However, when $\mathrm{Cu}\left(\mathrm{NO}_{3}\right)_{2} \cdot 3 \mathrm{H}_{2} \mathrm{O}$ was used, the size of the particles was $89 \mathrm{~nm}$, while it was $91 \mathrm{~nm}$ when $\mathrm{CuCl}_{2} \cdot 2 \mathrm{H}_{2} \mathrm{O}$ was used.
\end{abstract}

\section{Introduction}

The characteristics of particles change as the particle size decreases to nanosize. This change can be important if it is used to improve product characteristics and can be applied in numerous areas. The nanoparticles have been adapted to produce printable devices, flexible antennae, display, and circuit board in industries. To improve conductivity and increase the contact area, various shapes such as octahedral Au nanoparticle [1], and Ag cubic [2] were made in condensed surfactant phase. The spherical, cylindrical, and webshaped $\mathrm{Cu}$ and $\mathrm{CuO}$ were successfully synthesized by altering concentration of surfactants and $\mathrm{pH}$ of solutions in alcoholic media [3].
Additional tests were conducted using various surfactants to control particle size in the aqueous media. The concentration of the surfactants, bis (2-ethylhexyl) sulfosuccinate was used $[4,5]$, and PEG-400 were varied to determine the relationship of surfactant concentration with particle size. Because of PEG-400 and Au nano particle linkage, the particles cannot grow [6]. But except surfactant, chemical reaction time was the parameter to determine particle size [7].

Computer modelling was also used to determine which combination contributes to fine particle distribution and kinetics of nano particle formation [8], and Monte Carlo method was applied to predict final particle size [9]. Other attempt to improve nano particle characteristics is to change the medium from methanol to hexane to determine 
the relationship of particle size with carbon chain length [10] and in order to change the medium mixture of water, and methanol in varying ratios to verify the effect on particle size [11]. However, the fundamental mechanism of nano particles formation by means of carbon chain length, water and methanol ratios of mixing has not been proved.

The focus of this paper was to increase or decrease the conductivity by producing particles of various sizes in water. Reducing agent, concentration of metal ion, and so on were elements of changing conductivity [12]. In this paper, the conductivity was also changed by changing the concentration of ion, surfactant, and anions of copper compounds.

\section{Experimental}

Various sizes of copper nano particles were produced by varying the concentrations of copper ion and surfactants in solution. The concentration of surfactants is important in adjusting the size and amount of nano particles because surfactants hold copper ions as they are reduced. In this study in which $\mathrm{Cu}\left(\mathrm{NO}_{3}\right)_{2} \cdot 3 \mathrm{H}_{2} \mathrm{O}$ and $\mathrm{N}_{2} \mathrm{H}_{4} \cdot \mathrm{H}_{2} \mathrm{O}$ were held constant, and polyethylene glycol p-(1,1,3,3,-tetramethylbutyl)-phenyl ether(PGPPE) was changed from 0.1 to $0.5 \mathrm{~mol} / \mathrm{dm}^{3}$.

The method used is as follows: solutions of $100 \mathrm{~mL}$ $0.3 \mathrm{~mol} / \mathrm{dm}^{3} \mathrm{Cu}\left(\mathrm{NO}_{3}\right)_{2} \cdot 3 \mathrm{H}_{2} \mathrm{O}$ and $100 \mathrm{~mL}$ mixture of $0.1 \mathrm{~mol} / \mathrm{dm}^{3}$ to $0.5 \mathrm{~mol} / \mathrm{dm}^{3}$ PGPPE were prepared. These were mixed in solution and stirred at $300 \mathrm{rpm}$ and $25^{\circ} \mathrm{C}$. After mixing, $1 \mathrm{~mL}$ of $1.5 \mathrm{~mol} / \mathrm{dm}^{3} \mathrm{~N}_{2} \mathrm{H}_{4} \cdot \mathrm{H}_{2} \mathrm{O}$ was slowly added. The mixture was stirred until a constant color and temperature were maintained. This was followed by centrifugation at $6000 \mathrm{rpm}$ for $30 \mathrm{~min}$. The conductivity of supernatants and the size of particles were then measured by particle-sized analyser and TEM. PGPPE changed the conductivity with a long carbon change but also with $\mathrm{pH}$.

Table 1 shows the concentrations of various species used for the next set of experiments. In these experiments a $100 \mathrm{~mL}$ of $0.03 \mathrm{~mol} / \mathrm{dm}^{3}, \quad 0.15 \mathrm{~mol} / \mathrm{dm}^{3}, \quad 0.3 \mathrm{~mol} / \mathrm{dm}^{3}$, $1.5 \mathrm{~mol} / \mathrm{dm}^{3}$, and $3.0 \mathrm{~mol} / \mathrm{dm}^{3} \mathrm{Cu}\left(\mathrm{NO}_{3}\right)_{2} \cdot 3 \mathrm{H}_{2} \mathrm{O}$ was mixed with $100 \mathrm{~mL} 0.1 \mathrm{~mol} / \mathrm{dm}^{3}$ PGPPE. It was stirred at $300 \mathrm{rpm}$ and $25^{\circ} \mathrm{C}$. One $\mathrm{mL}$ of the corresponding amount of $\mathrm{N}_{2} \mathrm{H}_{4} \cdot \mathrm{H}_{2} \mathrm{O}$ was then added. Each solution was then put in a centrifuge at $6000 \mathrm{rpm}$ for $30 \mathrm{~min}$. The electric conductivity of solution with nano particles was measured while stirring at $300 \mathrm{rpm}$ by determining the resistance of the solution between platinum metal electrodes in cylindrical and arranged concentrically.

A test was conducted to compare the effect of using either $\mathrm{Cu}\left(\mathrm{NO}_{3}\right)_{2} \cdot 3 \mathrm{H}_{2} \mathrm{O}$ or $\mathrm{CuCl}_{2} \cdot 2 \mathrm{H}_{2} \mathrm{O}$ to control the conductivity. A solution of $100 \mathrm{~mL}$ of $0.3 \mathrm{~mol} / \mathrm{dm}^{3} \mathrm{Cu}\left(\mathrm{NO}_{3}\right)_{2} \cdot 3 \mathrm{H}_{2} \mathrm{O}$, $100 \mathrm{~mL}$ of $0.1 \mathrm{~mol} / \mathrm{dm}^{3}$ PEGPPE, and $60 \mathrm{~mL}$ of $1.5 \mathrm{~mol} / \mathrm{dm}^{3}$ hydrazine was made.

\section{Results and Discussion}

Figure 1 shows that the concentration of ion is a responsible factor for increasing the conductivity of the solution. As the concentration of ion increases, the size of particles also increases. This is possible because when the surfactant concentration is low, the particle growth improves. When ion
TABLE 1: Concentration of elements each solution with varying copper ion (unit: $\mathrm{mol} / \mathrm{dm}^{3}$ ).

\begin{tabular}{lcc}
\hline PGPPE & $\mathrm{Cu}\left(\mathrm{NO}_{3}\right)_{2} \cdot 3 \mathrm{H}_{2} \mathrm{O}$ & $\mathrm{N}_{2} \mathrm{H}_{4} \cdot \mathrm{H}_{2} \mathrm{O}$ \\
\hline 0.1 & 0.03 & 0.15 \\
0.1 & 0.15 & 0.75 \\
0.1 & 0.30 & 1.50 \\
0.1 & 1.50 & 7.50 \\
0.1 & 3.00 & 15.00 \\
\hline
\end{tabular}

concentration is high, the nucleation rate and the possibility of particle growing by collision of ions and primary particle are high. The results shown in Figures 1 indicate that there is a strong relationship between the particle size and the electric conductivity of aqueous solution. When the conductivity was increased in the wide range, the particle size also increased at the high concentration of solution. The mobility of ion in aqueous media with respect to copper ion concentration was the most pronounced factor to control the size of created copper nanometals in water. The electric conductivity varied in the range of 7 to $360 \mathrm{mS} / \mathrm{cm}$ when $\mathrm{Cu}\left(\mathrm{NO}_{3}\right)_{2} \cdot 3 \mathrm{H}_{2} \mathrm{O}$ dissolved in water from $0.03-3.0 \mathrm{~mol} / \mathrm{dm}^{3}$. In this condition, the size of nano particles was increased from 10.3 to $524.4 \mathrm{~nm}$ when copper ion was increased from 0.04 to $3.0 \mathrm{~mol} / \mathrm{dm}^{3}$.

Figure 2 shows that conductivity of solution was not affected of PGPPE concentration when PGPPE varied from 0.1 to $0.5 \mathrm{~mol} / \mathrm{dm}^{3}$ in the absent of copper ions in water. This would imply that the change of conductivity by only PFPPE is negligible, which was almost constant $0.01 \pm 0.003 \mathrm{mS} / \mathrm{cm}$. It is noted that the effect of PGPPE itself was not pronounced factor to change particle size and conductivity of aqueous solution. When the conductivity of the solution decreased using surfactant in the present of copper ion, the conductivity of the aqueous solution decreased widely than when without copper ion.

Figure 3 shows that when PGPPE, which is a surfactant, increased from $0.1 \mathrm{~mol} / \mathrm{dm}^{3}$ to $0.5 \mathrm{~mol} / \mathrm{dm}^{3}$, the conductivity decreased from $67.8 \mathrm{mS} / \mathrm{cm}$ to $55.8 \mathrm{mS} / \mathrm{cm}$. The decrease of conductivity, $12 \mathrm{mS} / \mathrm{cm}$, in the present of copper ion as change of PFPPE is 3 order bigger than that without copper ion $(0.006 \mathrm{mS} / \mathrm{cm})$. PGPPE is used as a surfactant and becomes get tangled like a net in water and inhibits the mobility of ions. It is reported that decreasing conductivity was affected by not only the mobility of ions, but also by carbon chain length of surfactant. It was also found in this research that when the concentration of surfactant increased, the particle size decreased from $89 \mathrm{~nm}$ to $22 \mathrm{~nm}$. These results are similar as that found with conductivity. There is strong evidence that the surfactant influences the size of the particles. As the concentration of the surfactant increases, the size of particles decreases resulting in poor conductivity. The surfactant interrupts the particle and ions as it is growing in size and shows that particle size is related to conductivity.

It is noted that the concentration of copper nitrate increases, the conductivity of the solution will increase regardless of the size of the particles. When copper ion disappeared due to metal reduction, the effect of nitrate on the conductivity of solution did not supersede that of cupper ion [13]. 


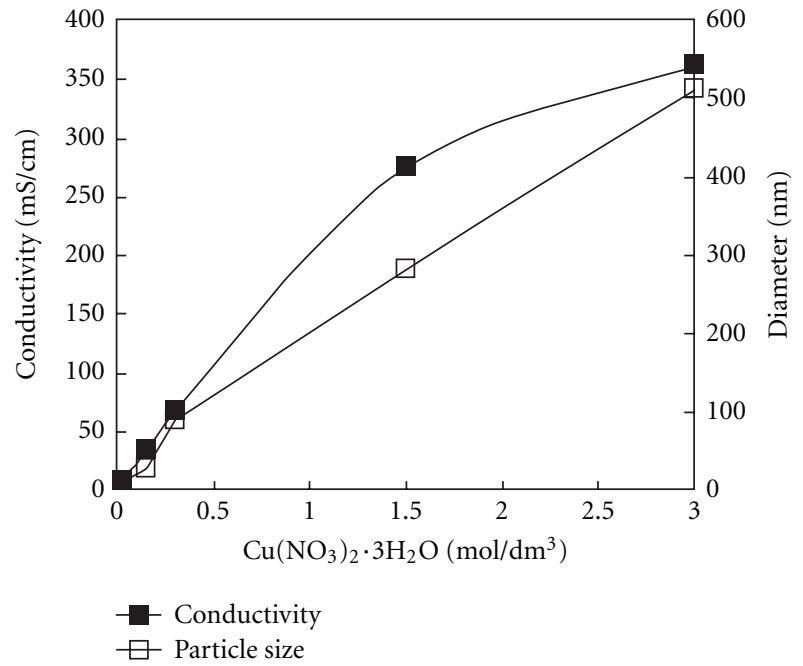

Figure 1: Conductivity and particle diameter as a function of concentration of $\mathrm{Cu}\left(\mathrm{NO}_{3}\right) 2 \cdot 3 \mathrm{H}_{2} \mathrm{O}$.

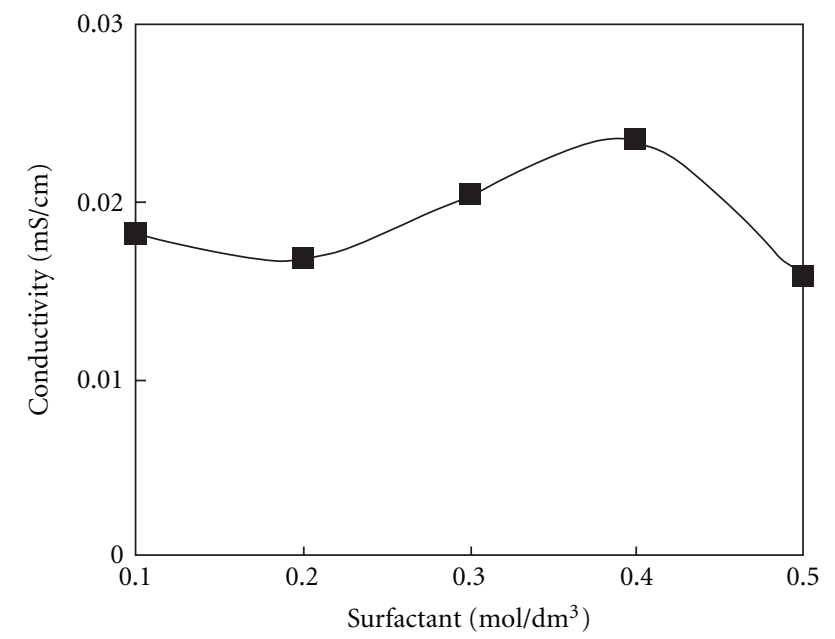

FIGURE 2: Conductivity as a function of surfactant concentration in the absent of copper ion.

On the other hand, when the surfactant concentration was changed from $0.1 \mathrm{~mol} / \mathrm{dm}^{3}$ to $0.5 \mathrm{~mol} / \mathrm{dm}^{3}$, the conductivity of the solution changed from $67.8 \mathrm{mS} / \mathrm{cm}$ to $58.4 \mathrm{mS} / \mathrm{cm}$, while the particle size decreased from $89 \mathrm{~nm}$ to $22 \mathrm{~nm}$.

Figure 4 shows that the anion used to control the conductivity was not a factor in controlling the particle size. A test was conducted to compare the effect of using either $\mathrm{Cu}\left(\mathrm{NO}_{3}\right)_{2} \cdot 3 \mathrm{H}_{2} \mathrm{O}$ or $\mathrm{CuCl}_{2} \cdot 2 \mathrm{H}_{2} \mathrm{O}$ to control the conductivity. $\mathrm{Cu}(\mathrm{NO} 3) 2 \cdot 3 \mathrm{H} 2 \mathrm{O}$ with PEGPPE was made with a resulting conductivity of $68 \mathrm{mS} / \mathrm{cm}$. Using the same volume of $\mathrm{CuCl}_{2} \cdot 2 \mathrm{H}_{2} \mathrm{O}$ instead of $\mathrm{Cu}\left(\mathrm{NO}_{3}\right)_{2} \cdot 3 \mathrm{H}_{2} \mathrm{O}$ resulted in a conductivity of $49 \mathrm{mS} / \mathrm{cm}$.

The resulting particle sizes of the solutions were $89 \mathrm{~nm}$ using $\mathrm{Cu}\left(\mathrm{NO}_{3}\right)_{2} \cdot 3 \mathrm{H}_{2} \mathrm{O}$ and $91 \mathrm{~nm}$ using $\mathrm{CuCl}_{2} \cdot 2 \mathrm{H}_{2} \mathrm{O}$. This shows that changing the anion was not factor of particle size even though the conductivity was changed.

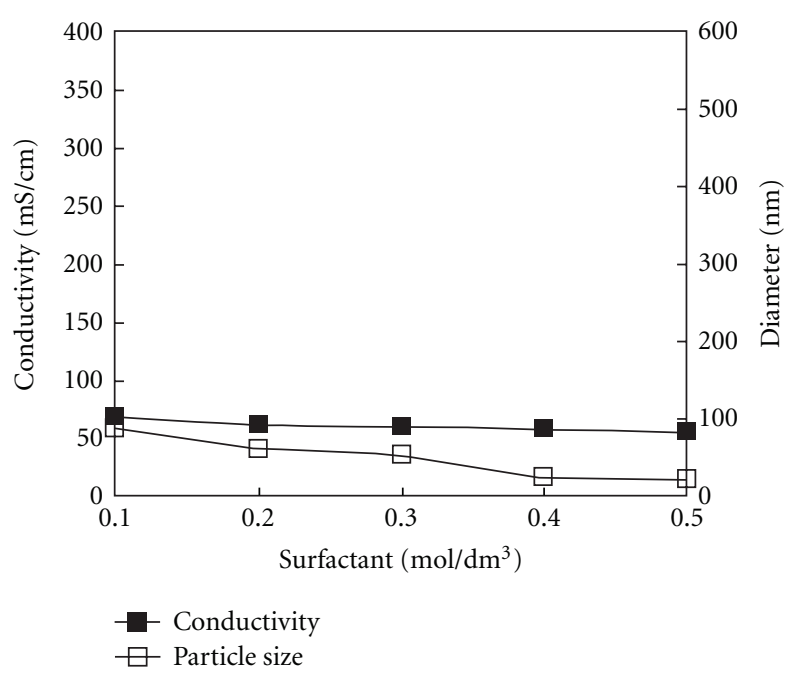

FIgURE 3: Conductivity and particle diameter as a function of surfactant concentration at $0.3 \mathrm{~mol} / \mathrm{dm}^{3}$ of $\mathrm{Cu}\left(\mathrm{NO}_{3}\right)_{2} \cdot 3 \mathrm{H}_{2} \mathrm{O}$.

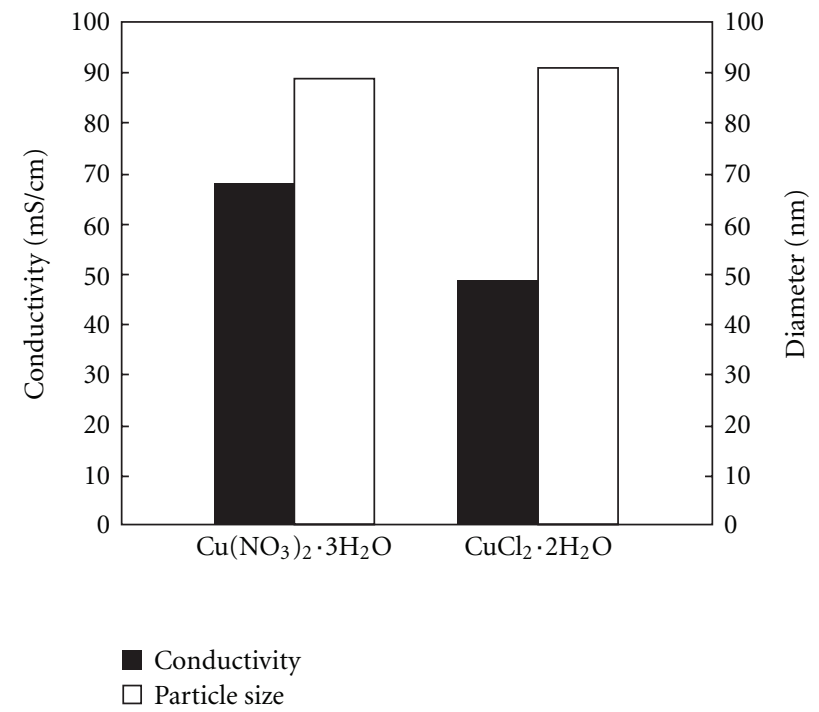

Figure 4: Conductivity of the solution and the size of the particles produced for two different solutions when $0.3 \mathrm{~mol} / \mathrm{dm}^{3}$ of $\mathrm{Cu}\left(\mathrm{NO}_{3}\right)_{2} \cdot 3 \mathrm{H}_{2} \mathrm{O}$ and $\mathrm{CuCl}_{2} \cdot 2 \mathrm{H}_{2} \mathrm{O}$ used, respectively.

Figure 5 shows that when particles were made in water by changing $\mathrm{Cu}$ ions in the present of surfactant. The $20 \mathrm{~nm}$ sized particles were reduced and immediately oxidized. Due to the high reactivity on large surface area, the nanocopper metal was oxidized in water. In this study all the nanosized copper particles were found to oxidize in water.

\section{Conclusion}

This work showed that by varying the conductivity of the solution the particles size was able to be controlled. Decreasing the conductivity had a corresponding effect on the particle size. The mobility of ion in aqueous media with respect 


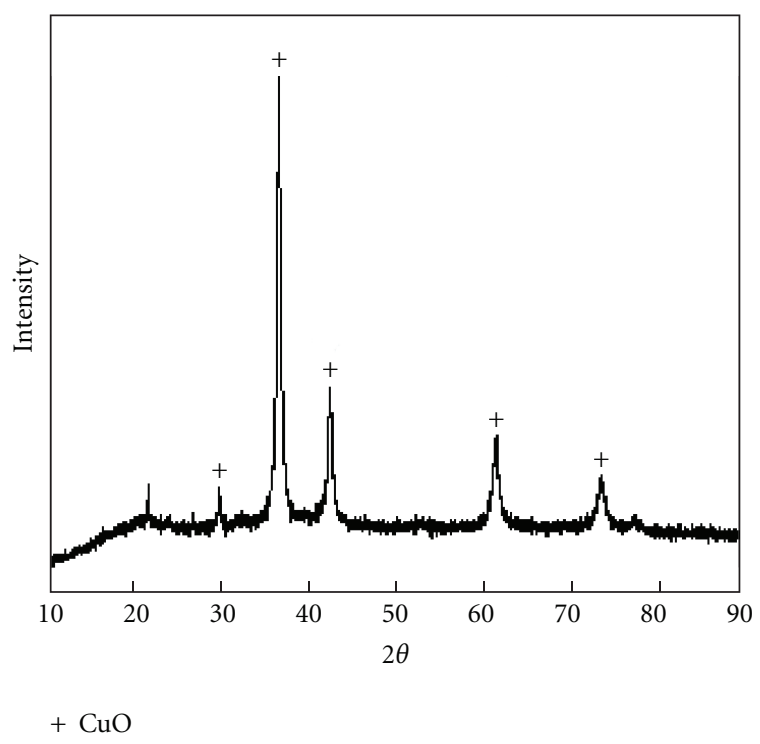

FIGURE 5: X-ray diffraction patterns of particles when $0.5 \mathrm{~mol} / \mathrm{dm}^{3}$ PGPPE with $0.3 \mathrm{~mol} / \mathrm{dm}^{3} \mathrm{Cu}\left(\mathrm{NO}_{3}\right)_{2} \cdot 3 \mathrm{H}_{2} \mathrm{O}$ and $1.5 \mathrm{~mol} / \mathrm{dm}^{3}$ was used.

to copper ion concentration was the most pronounced factor to control the size of created copper nanometals.

Various concentrations of surfactants and two anion $\mathrm{Cu}$-compounds used to vary the conductivity of the solution to verify the effect of electric conductivity of solution on the particle size. Decreasing the conductivity had a corresponding effect on the particle size. The electric conductivity was decreased from 67 to $56 \mathrm{mS} / \mathrm{cm}$ by adding surfactant from 0.1 to $0.5 \mathrm{~mol} / \mathrm{dm}^{3}$; consequently, the particle sizes were decreased from 89 to $21 \mathrm{~nm}$. Copper nitrate and copper chloride were used to verity the anion effect on electrical conductivity and particle sizes. This effect was not dependent on the kind of ions chosen to change the conductivity.

\section{Acknowledgments}

N.-S. Kim is grateful for the financial supports from STARS Award from Texas State, USA. and S.-M. Kang is grateful for the supports by Seokyeong University in 2009.

\section{References}

[1] C. Cao, S. Park, and S. J. Sim, "Seedless synthesis of octahedral gold nanoparticles in condensed surfactant phase," Journal of Colloid and Interface Science, vol. 322, no. 1, pp. 152-157, 2008.

[2] J. W. Yoo, S. M. Lee, H. T. Kim, and M. A. El-Sayed, "Shape control of platinum nanoparticles by using different capping organic materials," Bulletin of the Korean Chemical Society, vol. 25, no. 3, pp. 395-396, 2004.

[3] J. H. Hwang, J. M. Ucol, K.-W. Lee, A. Ortega, and N. S. Kim, "Shape modification of net shaped $\mathrm{CuO}$ and $\mathrm{u}$ nano particles for a percolation threshold using a chelating agent," Advanced Materials Research, vol. 399-401, pp. 766-773, 2012.

[4] K. Kimijima and T. Sugimoto, "Effects of the water content on the growth rate of $\mathrm{AgCl}$ nanoparticles in a reversed micelle system," Journal of Colloid and Interface Science, vol. 286, no. 2, pp. 520-525, 2005.

[5] K. E. Marchand, M. Tarret, J. P. Lechaire, L. Normand, S. Kasztelan, and T. Cseri, "Investigation of AOT-based microemulsions for the controlled synthesis of MoSx nanoparticles: an electron microscopy study," Colloids and Surfaces A, vol. 214, no. 1-3, pp. 239-248, 2003.

[6] X. F. Qiu, J. J. Zhu, and H. Y. Chen, "Controllable synthesis of nanocrystalline gold assembled whiskery structures via sonochemical route," Journal of Crystal Growth, vol. 257, no. 3-4, pp. 378-383, 2003.

[7] M. De Dios, F. Barroso, C. Tojo, M. C. Blanco, and M. A. López-Quintela, "Effects of the reaction rate on the size control of nanoparticles synthesized in microemulsions," Colloids and Surfaces A, vol. 270-271, no. 1-3, pp. 83-87, 2005.

[8] M. de Dios, F. Barroso, C. Tojo, and M. A. López-Quintela, "Simulation of the kinetics of nanoparticle formation in microemulsions," Journal of Colloid and Interface Science, vol. 333, no. 2, pp. 741-748, 2009.

[9] C. Tojo, M. C. Blanco, and M. A. López-Quintela, "Microemulsions as microreactors: a Monte Carlo simulation on the synthesis of particles," Journal of Non-Crystalline Solids, vol. 235-237, pp. 688-691, 1998.

[10] B. M. Kwak, J. E. Lee, J. H. Ahn, and T. H. Jeon, "Laser diffraction particle sizing by wet dispersion method for spray-dried infant formula," Journal of Food Engineering, vol. 92, no. 3, pp. 324-330, 2009.

[11] S. Praharaj, S. Jana, S. Kundu, S. Pande, and T. Pal, "Effect of concentration of methanol for the control of particle size and size-dependent SERS studies," Journal of Colloid and Interface Science, vol. 333, no. 2, pp. 699-706, 2009.

[12] K. N. Han and N. S. Kim, "Conductive inks manufactured with the help of low melting metals," Transactions of the Korean Society of Machine Tool Engineers, vol. 17, pp. 126-131, 2007.

[13] N. S. Kim, S. Y. Hwang, E. Y. Kim, and K. N. Han, "Synthesis of copper nano-ink in alcohol media," Japanese Journal of Applied Physics, vol. 49, no. 5, article 05EA04, 2010. 

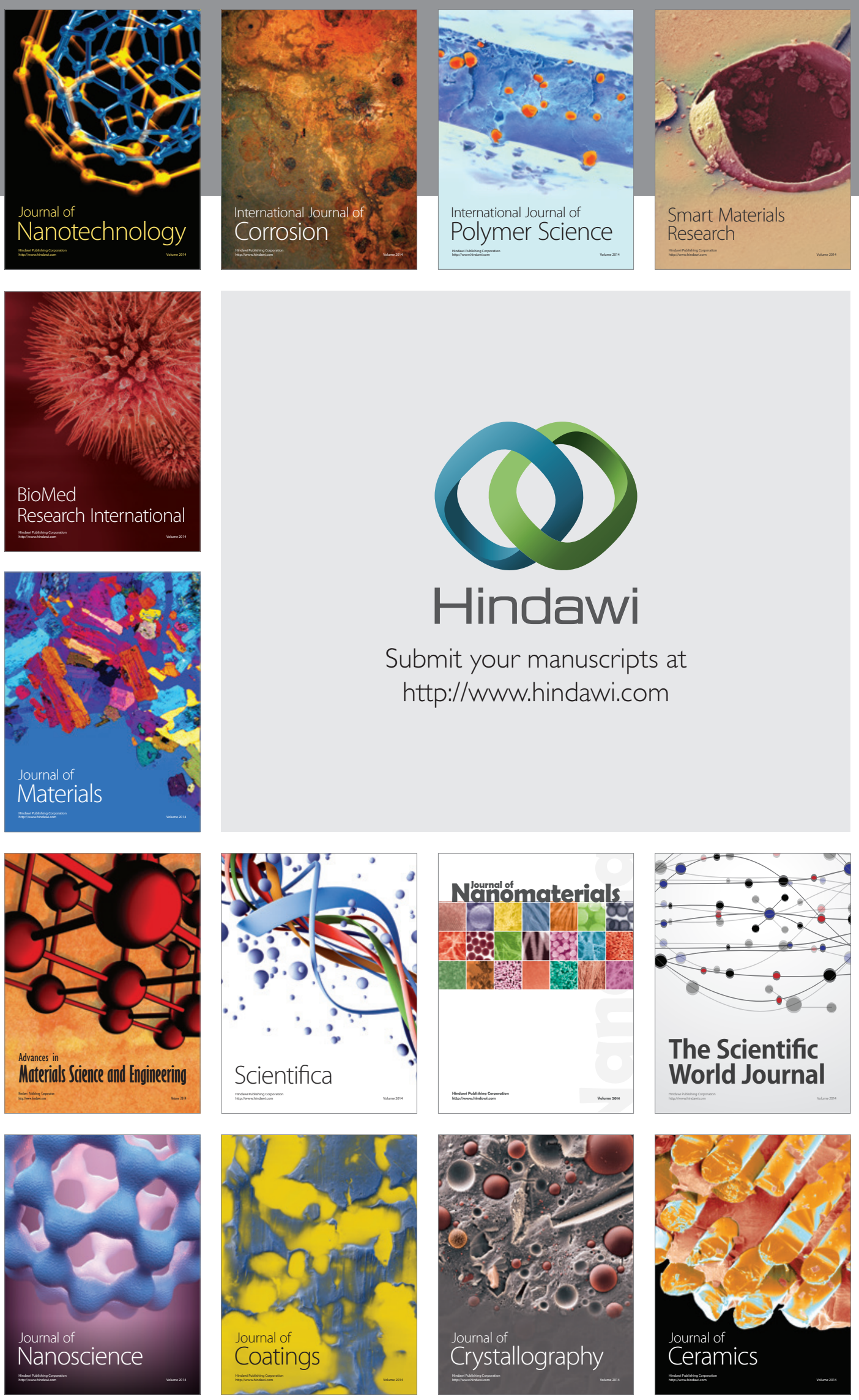

The Scientific World Journal

Submit your manuscripts at

http://www.hindawi.com

\section{World Journal}

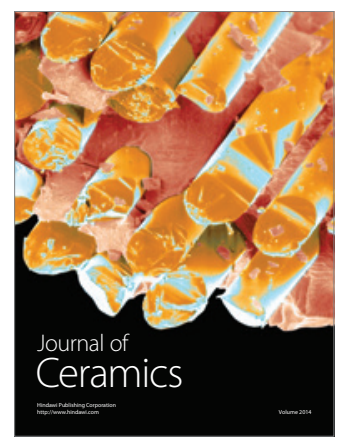

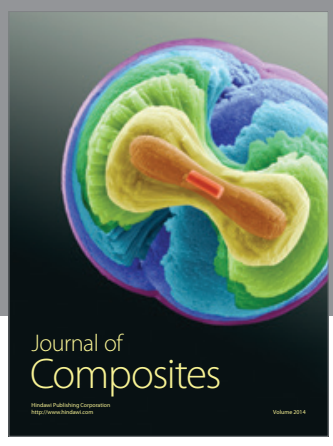
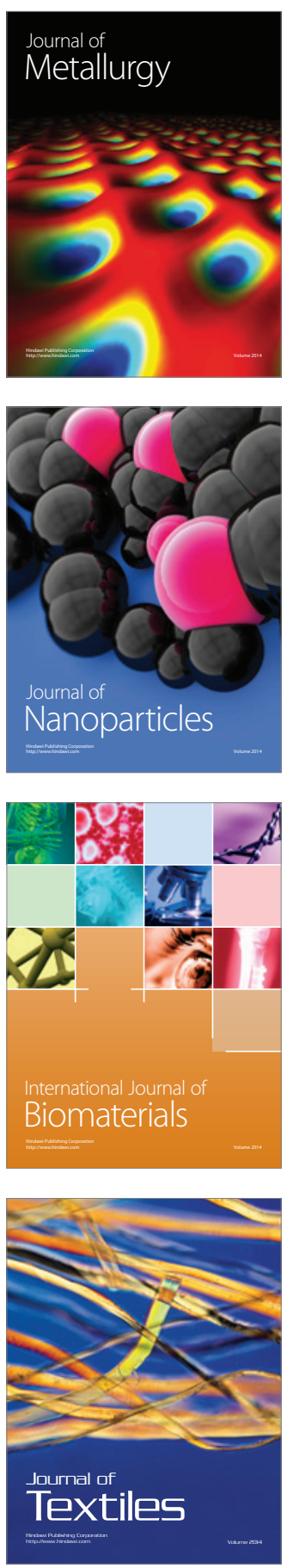